\title{
Management of Hepatocellular Carcinoma Patients with Portal Vein Thrombosis Using Three-Dimensional Conformal Radiotherapy
}

\author{
Ahmed Abo Gabal1*, Mohamed Lotayef1, Hoda Abd Elbaky¹, Maha Hassan'1, Heba Elzawahry², \\ Ekram Hamed $^{3}$
}

\author{
${ }^{1}$ Department of Radiation Oncology, National Cancer Institute, Cairo University, Cairo, Egypt \\ ${ }^{2}$ Department of Medical Oncology, National Cancer Institute, Cairo University, Cairo, Egypt \\ ${ }^{3}$ Department of Radio-Diagnosis, National Cancer Institute, Cairo University, Cairo, Egypt \\ Email: *ahmed.abogabal@nci.cu.edu.eg
}

How to cite this paper: Abo Gabal, A., Lotayef, M., Abd Elbaky, H., Hassan, M., Elzawahry, H. and Hamed, E. (2017) Management of Hepatocellular Carcinoma Patients with Portal Vein Thrombosis Using Three-Dimensional Conformal Radiotherapy. Journal of Cancer Therapy, 8, 579-590. https://doi.org/10.4236/jct.2017.86049

Received: April 16, 2017

Accepted: June 18, 2017

Published: June 21, 2017

Copyright (๑) 2017 by authors and Scientific Research Publishing Inc. This work is licensed under the Creative Commons Attribution International License (CC BY 4.0).

http://creativecommons.org/licenses/by/4.0/

c) $\underset{\mathrm{EY}}{\text { (i) Open Access }}$

\begin{abstract}
Objective: To determine the possible therapeutic gain of using three-dimensional conformal radiotherapy (3D-CRT) as a treatment option for portal vein tumor thrombus (PVTT) in patients with hepatocellular carcinoma (HCC) and to evaluate the tolerance and toxicity of using such treatment. Materials and methods: Sixty two patients were enrolled in this prospective study between June 2013 and August 2015. The clinical target volume (CTV) was the PVTT and the prescribed dose was $50 \mathrm{~Gy} / 25$ fractions. The median follow-up time was 7.4 months. Results: The thrombus crude response rate was $40.4 \%$ and the only significant prognostic factor for response was the thrombus size. Responders had significant better survival compared to non-responders with a median survival of 12.5 and 8 months respectively $(P<0.0001)$. The radiation toxicity profile was satisfactory. Conclusions: The results of this study suggest that radiotherapy should be considered as a safe treatment option for HCC patients with PVTT. It is effective not only for PVTT local control but also for survival, although prospective randomized trials are needed to confirm these results.
\end{abstract}

\section{Keywords}

Hepatocellular Carcinoma, Portal Vein Thrombosis, 3D Conformal Radiotherapy, Portal Vein Tumor Thrombus

\section{Introduction}

Hepatocellular carcinoma accounts for about $80 \%$ - 90\% of primary liver cancers. Worldwide it is ranked as the fifth most common cancer and the third most 
common cause of cancer mortality [1]. Eighty-five percent of cases occur in the developing countries [2]. In Egypt, HCC contributes about $8 \%$ of all cancers and it is ranked as second most common cancer in males and sixth in females [3]. Vascular invasion (especially invasion of the portal vein) is often noticed in patients with advanced HCC. The prognosis of patients with HCC is generally poor, but when accompanied by portal vein tumor thrombus, a median survival of 2.7 - 4.0 months was reported if left untreated [4].

Treatment strategies for HCC vary throughout the world. There is still no universal accepted form of treatment for HCC with PVTT and most of the guidelines encourage investigating new agents within clinical trials. According to Barcelona Clinic Liver Cancer (BCLC) guidelines patients with advanced stage disease are complicated by portal invasion but status with good performance are candidates for new antitumor agents [5]. The role of external beam radiotherapy in the treatment of HCC had been limited due to the risk of developing radiation-induced liver disease (RILD) [6]. With technological advances in radiation therapy, it became possible to deliver a higher dose of radiation while sparing healthy tissue from excessive irradiation. Recently, many retrospective and few phase 2 studies have shown that 3D-CRT is effective not only for tumor response but also for survival in HCC patients with PVTT. Median survival time of those patients was reported from 6 to 13 months [7] [8] [9].

Based on this background, this study was conducted to determine the possible therapeutic gain of using 3-DCRT as a treatment option for PVTT and to evaluate the tolerance and toxicity of using such treatment. The study also evaluated the thrombus response to radiotherapy and tried to define the prognostic factors related to both the patient and the thrombus.

\section{Materials and Methods}

\subsection{Patients}

Sixty two patients with hepatocellular carcinoma and portalvein tumor thrombus were enrolled in this prospective single arm study between June 2013 and August 2015. The inclusion criteria included: 1) Liver function of Child-Pugh class A or B; 2) Histological confirmation of HCC diagnosis or a characteristic tumor appearance in a dedicated imaging study (4-phase MDCT or dynamic contrast enhanced MRI); 3) WHO performance status of 0 - 2; 4) Patients with no prior history of radiotherapy to the liver; 5) Tumor thrombus in the main trunk and/or first branches of the portal vein proved by characteristic imaging. The exclusion criteria included: 1) Liver function of Child-Pugh class C; 2) Tumors which were occupying more than two-thirds of the Liver; 3) The presence of extra hepatic nodal or visceral metastases; 4) Patients with associated comorbidities or social factors that may interfere with radiotherapy delivery, treatment completion or follow up (apart from the present disease); 5) WHO performance status of 3 or 4 ; 6) Thrombus reaching Inferior Vena Cava; 7) Patients who refused to participate in this study. 
PVTT presence and its location were documented from the most recent imaging before treatment using the following criteria: 1) a low-attenuation intraluminal filling defect on portal phase; 2) an enhanced inner side of the filling defect on the arterial phase.

Institutional review board (IRB) approval was acquired as the study poses no harm on the participants. An informed consent was obtained from all the participants after explaining the purpose of the study, and they were informed that all the data will be presented anonymously.

\subsection{Radiation Therapy Treatment}

During the CT simulation the patients were scanned in the supine position with both arms raised above the head, both arterial and portal venous phase CT scans were performed. Slice thickness was $2.5 \mathrm{~mm}$. The patient was advised and trained to perform shallow respiration during the scan. A reference point was marked on the skin at the level of the xiphoid process with 3 radio opaque markers applied during the scan and their corresponding sites were tattooed. The clinical target volume (CTV) was the PVTT. The main hepatic tumor was not included in the CTV. The planning target volume (PTV) was generated using a $1.5-2 \mathrm{~cm}$ margin expansion around the CTV to allow for daily set-up variations and respiration with an extra $1 \mathrm{~cm}$ margin added to the PTV craniocaudally to accounts for the liver motion during respiration.

The following constraints were used for the 3D-CRT plan acceptance: 1) PTV covered by at least $95 \%$ of the prescribed dose; 2) Maximum accepted dose for hot spots within the PTV was $107 \%$ of the prescribed dose; 3 ) Liver volume receiving dose more than 30 Gy (V30) not exceeding 30\%; 4) Spinal cord maximum point dose not exceeding $45 \mathrm{~Gy}$; (5) The total dose received by $30 \%$ of both Kidneys not exceeding 20 Gy (V20) (Figure 1).

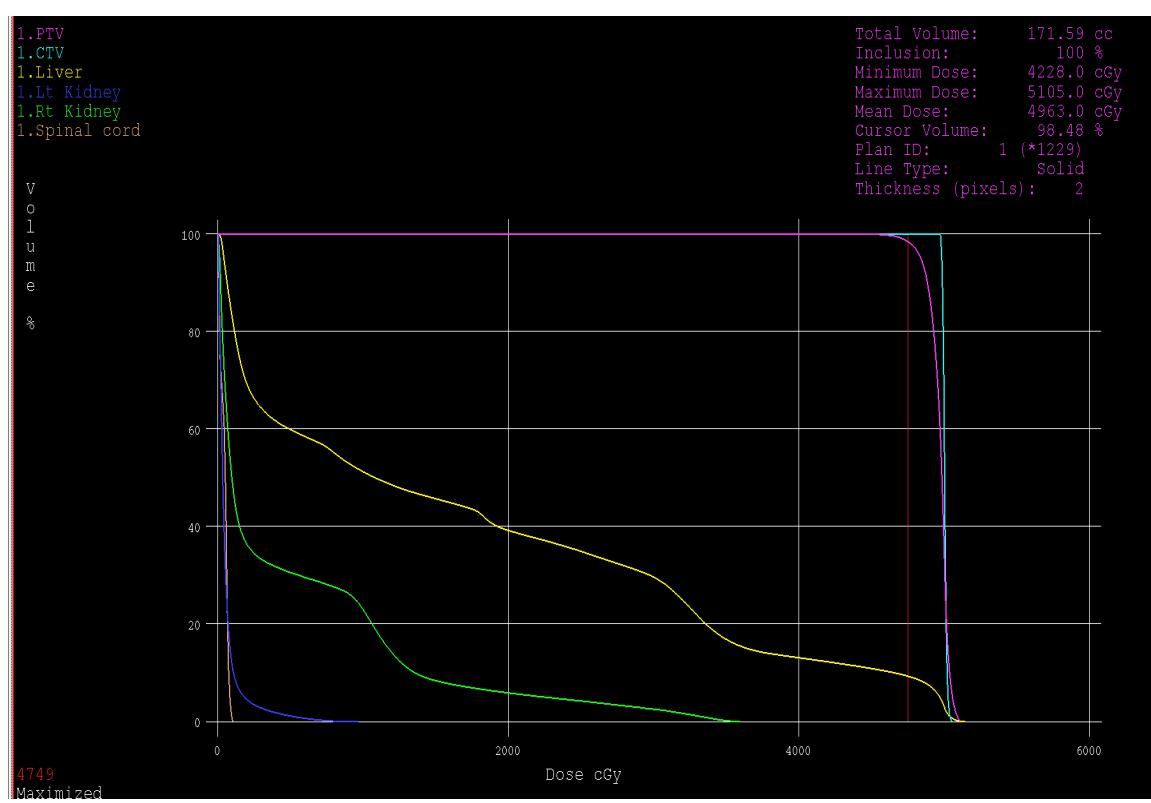

Figure 1. Dose volume histogram of a 3DCRT plan designed to treat one of the patients. 
A daily fraction of $2 \mathrm{~Gy}$ was prescribed to deliver a total dose of $50 \mathrm{~Gy}$ over 5 weeks. The treatment was prescribed at 5 fractions per week using a multi-energy linear accelerator after confirming the isocenter position using electronic portal imaging. The planned treatment schedule was designed to be kept as strict as possible. In case of treatment interruption, the missing treatment was compensated on weekends.

\subsection{Treatment Evaluation and Follow up}

During treatment the patients were monitored weekly by physical examination, complete blood cell count, liver function tests and bleeding profile. Patient's position during treatment was verified by weekly electronic portal imaging. Muliphasic CT, Liver function test, bleeding profile and AFP were done 4 - 6 weeks after the completion of the radiation course, and every 3 months thereafter. Full PVTT response was evaluated by determining the maximum reduction rate within 6 months after the end of radiotherapy. The response of the PVTT to treatment was assessed based on the "Response Evaluation Criteria in Solid Tumors (RECIST)" [10]. Treatment related toxicities were assessed using the Radiation Therapy Oncology Group (RTOG)/European Organization for Research and Treatment of Cancer (EORTC) Late Radiation Morbidity Scoring Scheme [11].

\subsection{Statistical Analysis}

Correlation between PVTT response and other variables was evaluated using the chi-square test or Fisher's exact test. Overall survival was estimated using the Kaplan-Meier method. Overall survival was measured from the date of diagnosis to the date of death or last follow up date. For univariate survival analyses, the log-rank test was used to evaluate differences. Potential prognostic variables that showed statistical significance in univariate analysis were used to perform multivariate analysis with the Cox proportional hazards model. All statistical analysis was performed using SPSS version 20.0. P-value $<0.05$ was considered statistically significant.

\section{Results}

Sixty two patients with hepatocellular carcinoma and portal vein tumor thrombus who met the inclusion criteria were enrolled in this prospective study between June 2013 and August 2015. Patient characteristics were summarized at Table 1.

Most of the patients were diagnosed in their sixth decade. Their age ranged between 43 and 75 years. The mean age was 61 years and male to female ratio was 9:1.Most of the patients had liver function of Child-Pugh class A. Only $18 \%$ of the patients had Child-Pugh class B. Forty three patients were +ve for HCV while only 5 patients were $+v e$ for HBV. Fourteen patients had no prior history of viral hepatitis. Patients were classified into 2 groups according to their serum AFP level with a cutoff value of $400 \mathrm{ng} / \mathrm{ml}$. Eighty five percent of the patients 
Table 1. Patient characteristics.

\begin{tabular}{|c|c|c|}
\hline & Frequency & Percent \\
\hline Number of patients & 62 & $100 \%$ \\
\hline Age (year) & $43-75($ mean 61$)$ & \\
\hline$\leq 60$ & 36 & $58.1 \%$ \\
\hline$>60$ & 26 & $41.9 \%$ \\
\hline \multicolumn{3}{|l|}{ Gender } \\
\hline Male & 56 & $90.3 \%$ \\
\hline Female & 6 & $9.7 \%$ \\
\hline \multicolumn{3}{|l|}{ Performance } \\
\hline 0 & 5 & $9.7 \%$ \\
\hline 1 & 39 & $80.6 \%$ \\
\hline 2 & 18 & $9.7 \%$ \\
\hline \multicolumn{3}{|l|}{ Child-Pugh Classification } \\
\hline $\mathrm{A}$ & 51 & $82.3 \%$ \\
\hline B & 11 & $17.7 \%$ \\
\hline \multicolumn{3}{|l|}{ T. bilirubin (mg/dl) } \\
\hline$<2$ & 53 & $85.5 \%$ \\
\hline $2-3$ & 5 & $8 \%$ \\
\hline$>3$ & 4 & $6.5 \%$ \\
\hline \multicolumn{3}{|l|}{ Albumin (gm/dl) } \\
\hline$>3.5$ & 41 & $66.1 \%$ \\
\hline $2.8-3.5$ & 19 & $30.6 \%$ \\
\hline$<2.8$ & 2 & $3.3 \%$ \\
\hline \multicolumn{3}{|l|}{ INR } \\
\hline$<1.7$ & 60 & $96.7 \%$ \\
\hline $1.7-2.3$ & 2 & $3.3 \%$ \\
\hline$>2.3$ & 0 & $0 \%$ \\
\hline \multicolumn{3}{|l|}{$\mathrm{HCV}$} \\
\hline$+\mathrm{ve}$ & 43 & $69.4 \%$ \\
\hline$-\mathrm{ve}$ & 19 & $30.6 \%$ \\
\hline \multicolumn{3}{|l|}{ HBV } \\
\hline$+\mathrm{ve}$ & 5 & $8.1 \%$ \\
\hline$-\mathrm{ve}$ & 57 & $91.9 \%$ \\
\hline \multicolumn{3}{|l|}{$\operatorname{AFP}(\mathrm{ng} / \mathrm{ml})$} \\
\hline$<400$ & 9 & $14.5 \%$ \\
\hline$\geq 400$ & 53 & $85.5 \%$ \\
\hline \multicolumn{3}{|l|}{ Tumor location } \\
\hline Hemiliver & 16 & $25.8 \%$ \\
\hline Bilobar (Both hemilivers) & 46 & $74.2 \%$ \\
\hline \multicolumn{3}{|l|}{ Tumor type } \\
\hline Unifocal & 10 & $16.1 \%$ \\
\hline Multiple/Diffuse & 52 & $83.9 \%$ \\
\hline \multicolumn{3}{|l|}{ Tumor maximum diameter } \\
\hline$(\mathrm{cm})$ & 18 & $29 \%$ \\
\hline $\begin{array}{l}\leq 6 \\
>6\end{array}$ & 44 & $71 \%$ \\
\hline \multicolumn{3}{|l|}{ Thrombus maximum } \\
\hline diameter $(\mathrm{cm})$ & 15 & $24.2 \%$ \\
\hline $\begin{array}{l}\leq 3 \\
>3\end{array}$ & 47 & $75.8 \%$ \\
\hline \multicolumn{3}{|l|}{ Thrombus site } \\
\hline PV main trunk & 15 & $24.2 \%$ \\
\hline PV branch & 5 & $8.1 \%$ \\
\hline PV trunk + branch(es) & 42 & $67.7 \%$ \\
\hline
\end{tabular}


had AFP levels above or equal to $400 \mathrm{ng} / \mathrm{ml}$. Sixteen patients had their tumor(s) confined to one hemiliver while 46 patients had tumors at both hemilivers. The percent of unifocal tumors and diffuse tumors were $16.1 \%$ and $83.9 \%$ respectively. Seventy one percent of the patients had tumors of a maximum diameter greater $6 \mathrm{~cm}$. For statistical analysis, PVTT were classified according to their size into 2 groups. Seventy nine percent of the patients had PVTT of a maximum diameter greater than $3 \mathrm{~cm}$. Forty two patients had thrombus in the main trunk and extending to the right, left or both portal vein branches.

Fifty one patients were able to complete the radiotherapy protocol and $47 \mathrm{pa}-$ tients among them had their treatment evaluated. The response was classified into complete response (CR), partial response (PR), stationary disease (SD) or progressive disease (PD) with a ratio of $8.5 \%, 31.9 \%, 55.3 \%$ and $4.3 \%$ respectively. Patients were grouped according to their PVTT response into responders and non-responders. The percentage of responders and non-responders were $40.4 \%$ and 59.6\% respectively. In regards of local response, multiple potential predictors were analyzed and the only significant one was the PVTT size (Table 2). Thrombi of a maximum diameter of $3 \mathrm{~cm}$ or less had significant better local response compared to those with maximum diameter greater than $3 \mathrm{~cm}$.

None of the 47 patients who were evaluated after treatment experienced grade- 3 or higher toxicities. Two patients were diagnosed by grade- 2 liver toxicity and only 1 patient complained of grade-2 GIT toxicity.

Table 2. Local response of the PVTT.

\begin{tabular}{|c|c|c|c|}
\hline & $\begin{array}{l}\text { Responders } \\
(\mathrm{CR}+\mathrm{PR})\end{array}$ & $\begin{array}{c}\text { Non-responders } \\
\quad(\mathrm{SD}+\mathrm{PD})\end{array}$ & $P$ value \\
\hline All patients & $19(40.4 \%)$ & $28(59.6 \%)$ & \\
\hline \multicolumn{4}{|l|}{ Age (years) } \\
\hline$\leq 60$ & $10(37 \%)$ & $17(63 \%)$ & \multirow[t]{2}{*}{0.401} \\
\hline$>60$ & $9(45 \%)$ & $11(55 \%)$ & \\
\hline \multicolumn{4}{|l|}{ Performance } \\
\hline 0 & $3(60 \%)$ & $2(40 \%)$ & \multirow{3}{*}{0.221} \\
\hline 1 & $13(41.9 \%)$ & $18(58.1 \%)$ & \\
\hline 2 & $3(27.3 \%)$ & $8(72.7 \%)$ & \\
\hline \multicolumn{4}{|l|}{ Child-Pugh } \\
\hline Classification & & & \multirow{3}{*}{0.6} \\
\hline $\mathrm{A}$ & $16(40 \%)$ & $24(60 \%)$ & \\
\hline $\mathrm{B}$ & $3(42.9 \%)$ & $4(57.1 \%)$ & \\
\hline \multicolumn{4}{|l|}{ AFP (ng/ml) } \\
\hline$<400$ & $4(44.4 \%)$ & $5(55.6 \%)$ & \multirow[t]{2}{*}{0.535} \\
\hline$\geq 400$ & $15(39.5 \%)$ & $23(60.5 \%)$ & \\
\hline \multicolumn{4}{|l|}{ Thrombus maximum } \\
\hline diameter $(\mathrm{cm})$ & & & \multirow{3}{*}{0.006} \\
\hline$\leq 3$ & $10(71.4 \%)$ & $4(28.6 \%)$ & \\
\hline$>3$ & $9(27.3 \%)$ & $24(72.7 \%)$ & \\
\hline \multicolumn{4}{|l|}{ Thrombus site } \\
\hline PV main trunk & $5(45.5 \%)$ & $6(54.5 \%)$ & \multirow{2}{*}{0.826} \\
\hline PV branch & $2(50 \%)$ & $2(50 \%)$ & \\
\hline PV trunk + branch(es) & $12(37.5 \%)$ & $20(62.5 \%)$ & \\
\hline
\end{tabular}


All the patients were followed up for at least 1 year or till death. The median follow up time was 7.4 months (Table 3). The median overall survival (OS) of all the patients in the study was 8.2 months. The 1-year and 2-year OS were $25.2 \%$ and $1.9 \%$ respectively (Figure 2). The PVTT response was the most significant prognostic factor by both univariate and multivariate analyses in terms of OS. Responders had significant better survival compared to non-responders with a median survival of 12.5 and 8 months respectively $(P<0.0001)$ (Figure 3$)$. The performance status was statistically significant for survival by both univariate $(P$ $=0.006)$ and multivariate $(P=0.03)$ analyses. The median survival for the patients with performance status 0,1 and 2 was $12.5,8.2$ and 5.2 months respectively (Figure 4).

Table 3. Overall survival.

\begin{tabular}{|c|c|c|c|c|c|c|}
\hline & $\begin{array}{l}\text { Number of } \\
\text { patients }\end{array}$ & $\begin{array}{l}\text { Median } \\
\text { Survival } \\
\text { (months) }\end{array}$ & $\begin{array}{c}1 \text {-year OS } \\
(\%)\end{array}$ & $\begin{array}{c}\text { 2-year OS } \\
(\%)\end{array}$ & $\begin{array}{c}\text { Univariate } \\
\text { analysis } \\
P \text { value }\end{array}$ & $\begin{array}{c}\text { Multivariate } \\
\text { analysis } \\
\text { P value }\end{array}$ \\
\hline All patients & 62 & 8.2 & $25.2 \%$ & $1.9 \%$ & & \\
\hline \multicolumn{7}{|l|}{ Age (years) } \\
\hline$\leq 60$ & 36 & 8.2 & $24.4 \%$ & $3.5 \%$ & \multirow[t]{2}{*}{0.876} & \\
\hline$>60$ & 26 & 8 & $26.4 \%$ & $0 \%$ & & \\
\hline \multicolumn{7}{|l|}{ Performance } \\
\hline 0 & 5 & 12.5 & $75 \%$ & $25 \%$ & \multirow{3}{*}{0.006} & \multirow{3}{*}{0.03} \\
\hline 1 & 39 & 8.2 & $26.9 \%$ & $0 \%$ & & \\
\hline 2 & 18 & 5.2 & $7.4 \%$ & $0 \%$ & & \\
\hline \multicolumn{7}{|l|}{ Child-Pugh } \\
\hline \multicolumn{7}{|l|}{ Classification } \\
\hline $\mathrm{A}$ & 51 & 8.2 & $30.6 \%$ & $2.4 \%$ & \multirow[t]{2}{*}{0.022} & \multirow[t]{2}{*}{0.158} \\
\hline B & 11 & 6.2 & $0 \%$ & $0 \%$ & & \\
\hline \multicolumn{7}{|l|}{ AFP (ng/ml) } \\
\hline$<400$ & 9 & 12.9 & $63.5 \%$ & $0 \%$ & \multirow[t]{2}{*}{0.096} & \\
\hline$\geq 400$ & 53 & 8 & $18.4 \%$ & $2.3 \%$ & & \\
\hline \multicolumn{7}{|l|}{ Tumor location } \\
\hline Hemi-liver & 16 & 11 & $39.1 \%$ & $7.8 \%$ & \multirow[t]{2}{*}{0.368} & \\
\hline Both hemilivers & 46 & 8 & $20.6 \%$ & $0 \%$ & & \\
\hline \multicolumn{7}{|l|}{ Tumor type } \\
\hline Unifocal & 10 & 12.2 & $53.3 \%$ & $13.3 \%$ & \multirow[t]{2}{*}{0.065} & \\
\hline Multiple/Diffuse & 52 & 7.9 & $20.2 \%$ & $0 \%$ & & \\
\hline \multicolumn{7}{|l|}{$\begin{array}{l}\text { Tumor max. } \\
\text { diameter }(\mathrm{cm})\end{array}$} \\
\hline$\leq 6$ & 18 & 8.2 & $30.3 \%$ & $0 \%$ & \multirow[t]{2}{*}{0.654} & \\
\hline$>6$ & 44 & 8 & $22.9 \%$ & $2.9 \%$ & & \\
\hline \multicolumn{7}{|l|}{ Thrombus site } \\
\hline PV main trunk & 15 & 8.2 & $22.2 \%$ & $7.4 \%$ & \multirow{3}{*}{0.655} & \\
\hline PV branch & 5 & 13 & $53.3 \%$ & $0 \%$ & & \\
\hline $\begin{array}{l}\text { PV trunk + } \\
\text { branch(es) }\end{array}$ & 52 & 8 & $23.2 \%$ & $0 \%$ & & \\
\hline & maximum \\
\hline diameter $(\mathrm{cm})$ & & & & & \multirow{3}{*}{0.018} & \multirow{3}{*}{0.187} \\
\hline$\leq 3$ & 15 & 9.2 & $36 \%$ & $9 \%$ & & \\
\hline$>3$ & 47 & 7.9 & $22 \%$ & $0 \%$ & & \\
\hline \multicolumn{7}{|l|}{ Tumor response } \\
\hline Responders & 19 & 12.5 & $56.5 \%$ & $6.3 \%$ & $<0.0001$ & $<0.0001$ \\
\hline Non responders & 28 & 8 & $17.2 \%$ & $0 \%$ & & \\
\hline
\end{tabular}




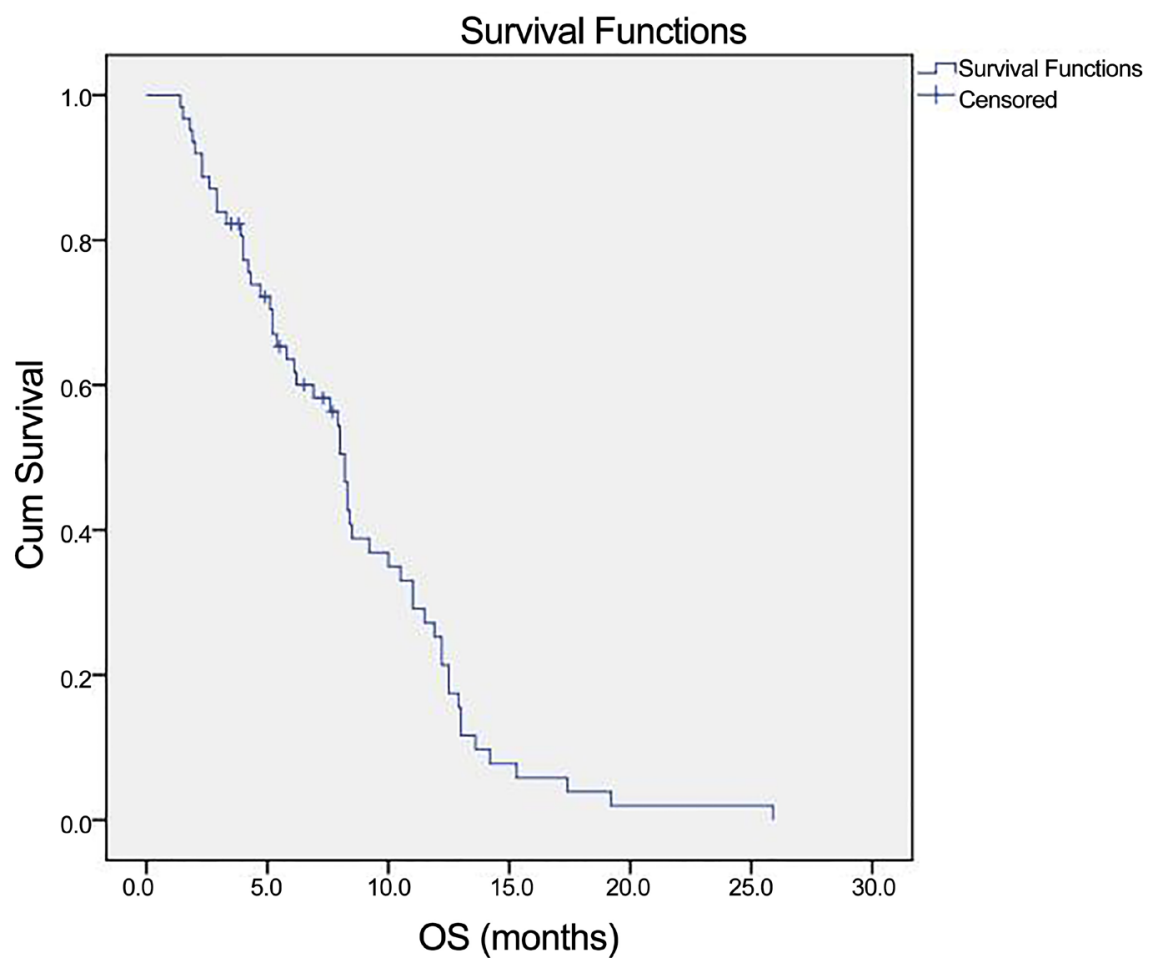

Figure 2. Survival of all 62 patients.

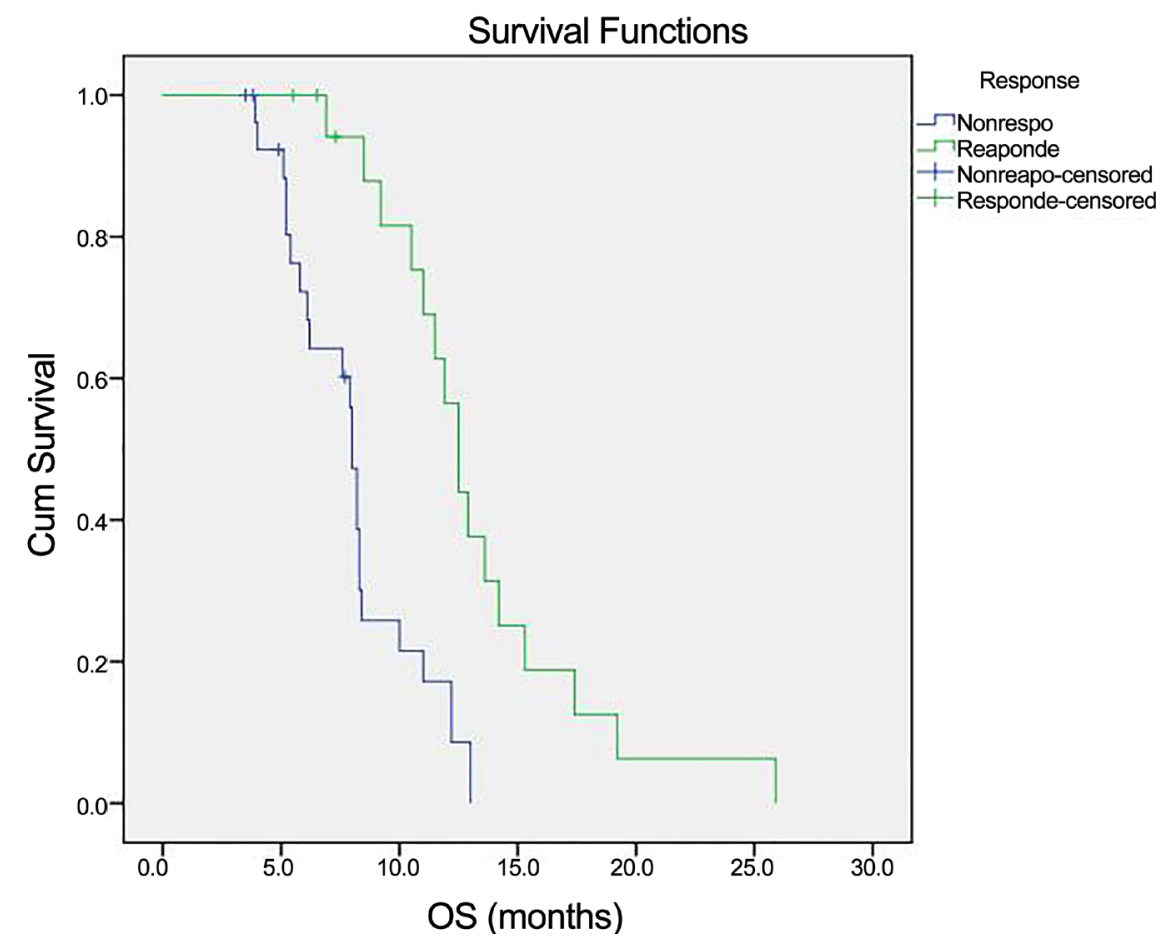

Figure 3. Relation between performance and OS.

Multiple studies investigated the response of PVTT to conventional radiation therapy [8] [9] [12] [13] [14] [15] [16]. Most of these studies were retrospective or small prospective trials. A wide range of radiotherapy doses was used and there was no clear definition for the target volume. Within the same trial, the 


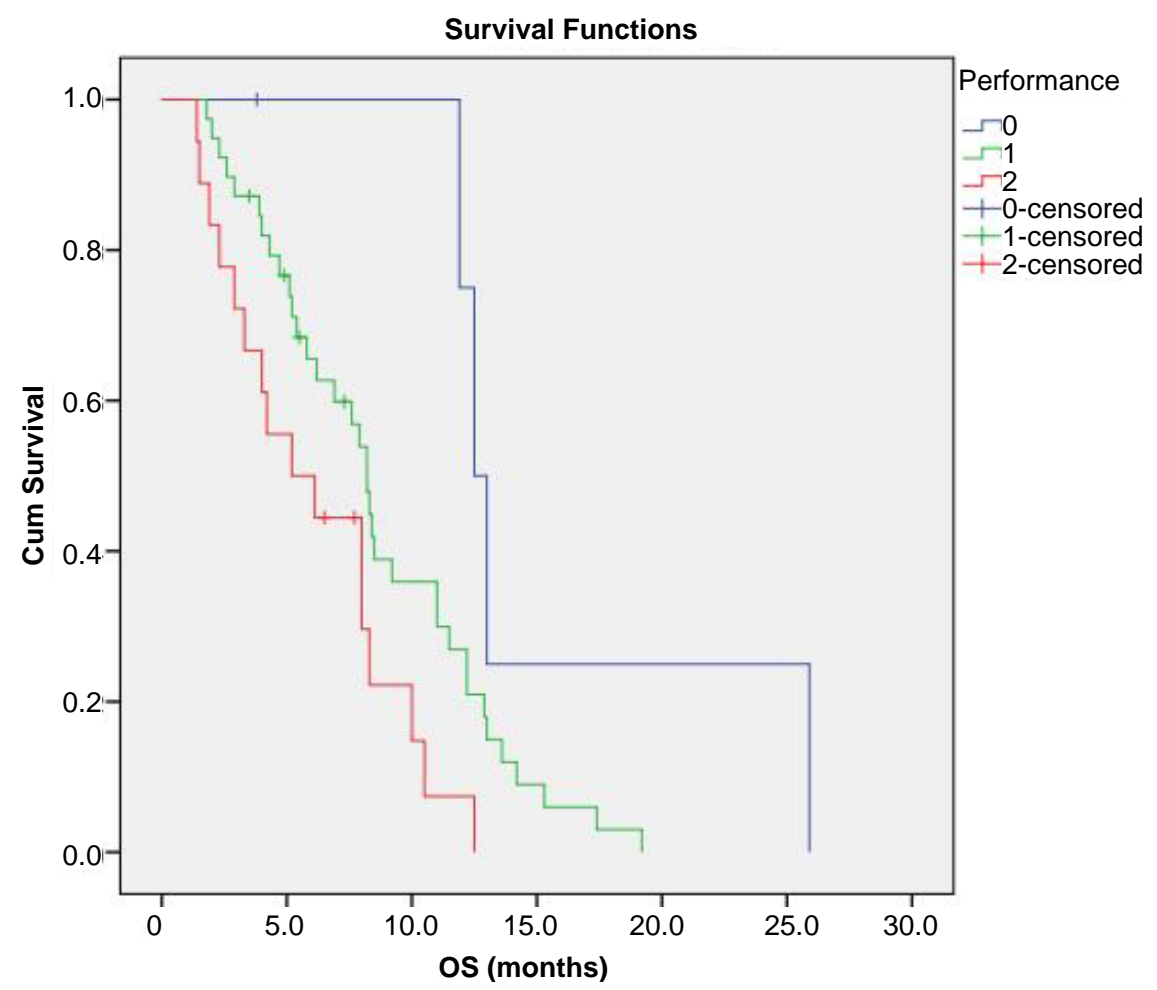

Figure 4. Relation between PVTT response to treatment and OS.

primary tumor was included in the target volume for some patients and excluded for others. In our study, we defined the clinical target volume as the PVTT and excluded the primary liver tumor for proper assessment of the thrombus response to radiotherapy.

Conventional fractionation of 50 Gy over 25 treatment fractions was prescribed to all the patients in this study. This dose was prescribed based on the earlier results by Haung et al. and Hou et al. when they reported significant lower survival for patients who were treated with RT doses lower than $50 \mathrm{~Gy}$ compared to those who received 50 Gy or higher [8] [12].

In this study, $17.7 \%$ of the patients were not able to complete the radiotherapy course. Moreover, 4 out of 51 patients who completed the protocol did not have post-treatment evaluation because they died before the scheduled follow-up date. Huang et al. also categorized $48 \%$ of their patients as "missing status" [8]. In a similar study conducted by Lin et al, 29 out of 43 patients received incomplete radiotherapy and died before evaluation [7].

The response of the PVTT was evaluated in multiple recent retrospective trials, the complete and partial response rates were reported from $5.8 \%$ to $20.8 \%$ and from $19.4 \%$ to $55.6 \%$ respectively [8] [12] [13]. The reason for this wide range is the discrepancy is the previous trials design. As mentioned before, most of the trials were retrospective and included patients who were treated with different radiation doses, unclear definition of target volume and different radiotherapy techniques including 2D, 3D-CRT, IMRT, SBRT and proton therapy. The results of these trials are comparable with our results, the complete and partial response rates were $8.5 \%$ and $31.9 \%$ respectively. 
After analyzing the potential predictors for PVTT response, the only significant factor was the thrombus size. PVTT of maximum diameter of $3 \mathrm{~cm}$ or less had significant better response rate compared to those of maximum diameter larger than $3 \mathrm{~cm}(P=0.006)$. These results confirm the results published by Toya et al on 2007 when they defined portal vein tumor thrombi of $3 \mathrm{~cm}$ maximum diameter or less as a favorable factor for local response [14].

The median survival for all the patients in our study was 8.3 months. The 1year OS and 2 years OS rates were $25.2 \%$ and $1.9 \%$ respectively. Multiple predictors of survival were identified in this study. The PVTT response was the most significant prognostic factor by both univariate and multivariate analyses in terms of OS. Responders had significant better survival compared to nonresponders with a median survival of 12.5 and 8 months respectively. These results are confirming the results published earlier by Kim et al when they found a significant correlation between PVTT response and survival. The median survival which was reported in their study was 15 months for responders and 8 months for non-responders [15]. In this study, performance status as a predictor of survival was found to be statistically significant by both univariate and multivariate analyses. Similar results were published on 2012 by Rim et al. when they correlated between poor performance status and worse survival outcomes [13].

By univariate analysis, patients with Child-Pugh liver function class A had significant better survival compared to those with class B. By multivariate analysis, the difference was not statistically significant. The same was observed with lower serum AFP level, patients with AFP level below $400 \mathrm{ng} / \mathrm{ml}$ had better survival but that was only significant with univariate analysis.

Table 4. Table showing trials using Radiotherapy as a single treatment modality for HCC with PVTT including our trial.

\begin{tabular}{|c|c|c|c|c|c|c|c|}
\hline Study & $\begin{array}{c}\text { No. of } \\
\text { patients }\end{array}$ & Design & Type of treatment & $\begin{array}{l}\text { CR } \\
(\%)\end{array}$ & $\begin{array}{l}\mathrm{PR} \\
(\%)\end{array}$ & $\begin{array}{l}\text { Median survival } \\
\text { (months) }\end{array}$ & $\begin{array}{c}1-y \text { OS } \\
(\%)\end{array}$ \\
\hline Our study & 62 & Prospective & 3DCRT to PVTT & $8.5 \%$ & $31.9 \%$ & $\begin{array}{c}\text { All patients: } 8.2 \\
\text { Responders: } 12.5 \\
\text { Non responders: } 8\end{array}$ & $\begin{array}{c}\text { All patients: } 25.2 \\
\text { Responders: } 56.5 \\
\text { Non responders: } 17.2\end{array}$ \\
\hline $\begin{array}{l}\text { Rim et al. } \\
(2012)\end{array}$ & 45 & Retrospective & $\begin{array}{l}\text { 3DCRT to PVTT } \pm \\
\text { Liver tumor }\end{array}$ & $6.7 \%$ & $55.6 \%$ & $\begin{array}{l}\text { All patients: } 11.2 \\
\text { Responders: } 16.7 \\
\text { Non responders: } 8\end{array}$ & $\begin{array}{c}\text { Responders: } 63.7 \\
\text { Non responders: } 28\end{array}$ \\
\hline $\begin{array}{l}\text { Hou et al. } \\
\text { (2012) }\end{array}$ & 128 & Retrospective & 3DCRT to PVTT & $20.8 \%$ & $33.3 \%$ & 8.2 & - \\
\hline $\begin{array}{l}\text { Huang et } \\
\text { al. (2009) }\end{array}$ & 326 & Retrospective & $\begin{array}{c}\text { 3DCRT/IMRT to } \\
\text { PVTT }\end{array}$ & $5.8 \%$ & $19.4 \%$ & $\begin{array}{l}\text { All patients: } 4 \\
\text { CR: } 13.3 \\
\text { PR: } 11.6 \\
\text { SD: } 9 \\
\text { PD: } 4.5\end{array}$ & - \\
\hline $\begin{array}{l}\text { Toya et al. } \\
\text { (2007) }\end{array}$ & 38 & Retrospective & $\begin{array}{l}\text { 3DCRT to PVTT } \pm \\
\text { Liver tumor }\end{array}$ & $15.8 \%$ & $28.9 \%$ & 9.6 & 39.4 \\
\hline $\begin{array}{l}\text { Lin et al. } \\
(2006)\end{array}$ & $22 / 21$ & Prospective & $\begin{array}{l}\text { SBRT/3DCRT to } \\
\text { PVTT }\end{array}$ & $\begin{array}{r}\text { Crude } \\
75 \%\end{array}$ & $\begin{array}{l}\text { ponse } \\
3 \%\end{array}$ & $6 / 6.7$ & - \\
\hline $\begin{array}{l}\text { Kim et al. } \\
\quad(2005)\end{array}$ & 59 & Retrospective & $\begin{array}{l}\text { 3DCRT to PVTT } \\
\text { and Liver tumor }\end{array}$ & $6.8 \%$ & $39 \%$ & $\begin{array}{c}\text { Responders: } 10.7 \\
\text { Non responders: } 5.3\end{array}$ & $\begin{array}{c}\text { Responders: } 40.7 \\
\text { Non responders: } 25\end{array}$ \\
\hline
\end{tabular}


None of our patients experienced grade- 3 or higher toxicities. Multiple earlier trials also reported a favorable toxicity profile with $0 \%$ grade- 3 or higher toxicities when they used radiotherapy in the treatment of PVTT [7] [8] [12] [14] [16]. Our results are supporting the results of the previous trials that considered radiotherapy as a safe treatment for HCC with PVTT.

During post-treatment follow up, most of our patients claimed a significant improvement of their initially symptoms (mainly abdominal pain) but unfortunately our study was not designed to assess the subjective improvement of the symptoms (Table 4 ).

\section{Conclusion}

The results of this study suggest that radiotherapy should be considered as a safe treatment option for HCC patients with PVTT. It is effective not only for PVTT local control but also for survival, although prospective randomized trials are needed to confirm these results.

\section{Conflicts of Interest}

None of the authors has any conflict of interest to declare.

\section{References}

[1] Siegel, R., Naishadham, D. and Jemal, A. (2012) Cancer Statistics. CA: A Cancer Journal for Clinicians, 62, 10-29. https://doi.org/10.3322/caac.20138

[2] Center, M.M. and Jemal, A. (2011) International Trends in Liver Cancer Incidence Rates. Cancer Epidemiology, Biomarkers \& Prevention, 20, 2362-2368. https://doi.org/10.1158/1055-9965.EPI-11-0643

[3] El Bolkainy, et al. (2016) Pathology of Cancer. National Cancer Institute Press, Cairo.

[4] Minagawa, M. and Makuuchi, M. (2006) Treatment of Hepatocellular Carcinoma Accompanied by Portal Vein Tumor Thrombus. The World Journal of Gastroenterology, 12, 7561-7567. https://doi.org/10.3748/wjg.v12.i47.7561

[5] Llovet, J.M. (2005) Updated Treatment Approach to Hepatocellular Carcinoma. The Journal of Gastroenterology, 40, 225-235. https://doi.org/10.1007/s00535-005-1566-3

[6] Dawson, L.A. and Tenm Haken, R.K. (2005) Partial Volume Tolerance of the Liver to Radiation. Seminars in Radiation Oncology, 15, 279-283. https://doi.org/10.1016/j.semradonc.2005.04.005

[7] Lin, C.S., Jen, Y.M., Chiu, S.Y., et al. (2006) Treatment of Portal Vein Tumor Thrombosis of Hepatoma Patients with Either Stereotactic Radiotherapy or ThreeDimensional Conformal Radiotherapy. Japanese Journal of Clinical Oncology, 36, 212-217. https://doi.org/10.1093/jico/hyl006

[8] Huang, Y., Hsu, H., Wang, C., et al. (2009) The Treatment Responses in Cases of Radiation Therapy to Portal Vein Thrombosis in Advanced Hepatocellular Carcinoma. International Journal of Radiation Oncology, Biology, Physics, 73, 1155 1163. https://doi.org/10.1016/j.ijrobp.2008.06.1486

[9] Yoon, S.M., Lim, Y.S., Won, H.J., et al. (2012) Radiotherapy plus Transarterial Chemoembolization for Hepatocellular Carcinoma Invading the Portal Vein: 
Long-Term Patient Outcomes. International Journal of Radiation Oncology, Biology, Physics, 82, 2004-2011. https://doi.org/10.1016/j.ijrobp.2011.03.019

[10] Therasse, P., Arbuck, S.G., Eisenhauer, E.A., et al. (2000) New Guidelines to Evaluate the Response to Treatment in Solid Tumors. The Journal of the National Cancer Institute, 92, 205-216. https://doi.org/10.1093/jnci/92.3.205

[11] Cox, J.D., Stetz, J. and Pajak, T.F. (1995) Toxicity Criteria of the Radiation Therapy Oncology Group (RTOG) and the European Organization for Research and Treatment of Cancer (EORTC). International Journal of Radiation Oncology, Biology, Physics, 31, 1341-1346. https://www.ncbi.nlm.nih.gov/pubmed/7713792

[12] Hou, J., Zeng, Z.-C., et al. (2012) Influence of Tumor Thrombus Location on the Outcome of External-Beam Radiation Therapy in Advanced Hepatocellular Carcinoma with Macrovascular Invasion. International Journal of Radiation Oncology, Biology, Physics, 84, 362-368.

[13] Rim, C., Yang, D., Park, Y., et al. (2012) Effectiveness of High-Dose Three Dimensional Conformal Radiotherapy in Hepatocellular Carcinoma with Portal Vein Thrombosis. Japanese Journal of Clinical Oncology, 42, 721-729. https://doi.org/10.1093/jjco/hys082

[14] Toya, R., Murakami, R., Baba, Y., et al. (2007) Conformal Radiation Therapy for Portal Vein Tumor Thrombosis of Hepatocellular Carcinoma. Radiotherapy and Oncology, 84, 266-271.

[15] Kim, D.Y., Park, W., Lim, D.H., et al. (2005) Three-Dimensional Conformal Radiotherapy for Portal Vein Thrombosis of Hepatocellular Carcinoma. Cancer, 103, 2419-2426. https://doi.org/10.1002/cncr.21043

[16] Zhang, X.B., Wang, J.H., et al. (2009) Hepatocellular Carcinoma with Main Portal Vein Tumor Thrombus: Treatment with 3-Dimensional Conformal Radiotherapy after Portal Vein Stenting and Transarterial Chemoembolization. Cancer, 115, 1245-1252. https://doi.org/10.1002/cncr.24139

\section{Submit or recommend next manuscript to SCIRP and we will provide best} service for you:

Accepting pre-submission inquiries through Email, Facebook, LinkedIn, Twitter, etc. A wide selection of journals (inclusive of 9 subjects, more than 200 journals)

Providing 24-hour high-quality service

User-friendly online submission system

Fair and swift peer-review system

Efficient typesetting and proofreading procedure

Display of the result of downloads and visits, as well as the number of cited articles

Maximum dissemination of your research work

Submit your manuscript at: http://papersubmission.scirp.org/

Orcontact jct@scirp.org 